\title{
EL IMPACTO TERRITORIAL DE LA CRISIS SANITARIA
}

\author{
Pablo Guerrero Vázquez \\ Investigador Fundación Manuel Giménez Abad
}

Cómo citar este artículo / Citation: Guerrero Vázquez, P. (2021). El impacto territorial de la crisis sanitaria. Tudela Aranda, J. (coord.)

Estado Autonómico y covid-19,

Colección Obras colectivas, Fundación Manuel Giménez Abad, Zaragoza.

DOI: https://doi.org/10.47919/FMGA.OC21.0207

SUMARIO: I. INTRODUCCIÓN - II. EL ESTADO AUTONÓMICO EN UNA NORMALIDAD FINGIDA: LOS DÍAS PREVIOS A LA EXCEPCIÓN - III. ESTADO DE ALARMA SANITARIA Y ESTADO AUTONÓMICO (PRIMERA PARTE) - IV. EL OXIMORÓN DE LA NUEVA NORMALIDAD - V. ESTADO DE ALARMA SANITARIA Y ESTADO AUTONÓMICO (SEGUNDA PARTE)

\section{INTRODUCCIÓN}

Desde hace varias ediciones, gracias a la generosidad de José Tudela, tengo la oportunidad de asistir al Seminario "Debates sobre el Estado autonómico"1, que reúne anualmente a los más destacados expertos en materia territorial. El valor que tiene asistir a un foro como éste es, sin lugar a duda, incalculable. La posibilidad de aprender de la mejor doctrina, a lo largo de sesiones que se desarrollan con un formato muy flexible, es una oportunidad única; y más si cabe para un joven profesor.

Esta obra colectiva trae causa de la última edición del Seminario, celebrada en octubre de 2020, pocos días después de que se declarase en España un segundo estado de alarma por RD 926/2020, de 25 de octubre. La situación sanitaria que atravesaba nuestro país aquellos días provocó, lamentablemente, que dicho evento no fuese celebrado en el Monasterio de Piedra, como es

\footnotetext{
${ }^{1}$ Coorganizadas por la Fundación Manuel Giménez Abad y la Fundación Konrad Adenauer.
} 
costumbre, sino de manera telemática. Sin embargo, en mi caso, ni siquiera está particularidad me permitió asistir a aquella edición. Circunstancias familiares, las peores que cabe imaginar, pero tan comunes aquellos días en tantos cientos de familias españolas, me lo impidieron. Pese a ello, se me ha brindado la oportunidad de participar en estas páginas, que firman grandes maestros del Derecho Constitucional. Y aunque con osadía he aceptado el reto, tan solo lo he hecho con la esperanza de desmerecer lo mínimo posible.

En este trabajo abordaré algunas de las repercusiones que la crisis sanitaria ha tenido para el Estado de las autonomías, centrándome especialmente en la coyuntura aragonesa. En parte porque la Fundación Manuel Giménez Abad presta servicio a las Cortes de Aragón. Y en parte, también, porque en Aragón han acontecido una serie de peculiaridades cuyo estudio puede ser atractivo desde una perspectiva nacional -v. gr., una prematura segunda ola durante la veraniega nueva normalidad, o una forma sui generis de reaccionar a la situación epidemiológica vivida durante los primeros compases del otoño-. A todo ello se dedican las siguientes líneas que, pese a haber sido redactadas con la voluntad de no ser meramente descriptivas, seguirán un orden cronológico. Con tal propósito se aborda, en primer lugar, el papel que jugaron las CCAA durante las últimas semanas de presunta normalidad (II). En segundo lugar, se analiza la repercusión que tuvo para nuestra forma de Estado la declaración del estado de alarma de marzo (III). A continuación, el trabajo se detiene en las limitaciones que tuvo el ámbito decisional autonómico en un contexto de normalidad que no era tal (IV). Y, por último, se abordan las repercusiones territoriales del estado de alarma declarado en octubre y, muy especialmente, la posibilidad de descentralizar la gestión de la excepción.

\section{EL ESTADO AUTONÓMICO EN UNA NORMALIDAD FINGIDA: LOS DÍAS PREVIOS A LA EXCEPCIÓN}

Los gobiernos de Canarias, La Rioja y Cataluña fueron las primeras autoridades que tuvieron que enfrentarse al Sars-CoV-2, en un contexto en el que todavía estaba extendida la creencia de que la pandemia no iba a afectar a España. O, al menos, que no lo iba a hacer con igual intensidad que en otras partes del globo que comenzaban a estar peligrosamente cerca -como es el caso de Italia-. 
El 24 de febrero de 2020 se constató que un ciudadano italiano, hospedado en un hotel del suroeste de Tenerife, había desarrollado la contagiosa enfermedad conocida como covid-19 y, en consecuencia, se hacía necesario confinar a cuantos allí se encontraban -hospedados o trabajando-. Esta medida fue adoptada por Orden de 24 de febrero de la Consejera de Sanidad del Gobierno de Canarias, modificada parcialmente tres días después, y ratificadas ambas, como era preceptivo al verse limitados o restringidos derechos fundamentales, por un órgano judicial (artículo 8.6 Ley 29/1998, de 13 de julio, reguladora de la Jurisdicción Contencioso-administrativa (LJCA, en adelante)).

La decisión del ejecutivo canario se fundamentaba, principalmente, en el artículo 2 LO 3/1986, de 14 de abril, de medidas especiales en materia de salud pública (LOSP, en adelante). Y no en el artículo 3 de esta norma, que sería unos meses después la disposición de referencia de los diferentes gobiernos autonómicos para justificar un amplio elenco de medidas adoptadas en materia de salud pública. Pero no adelantemos acontecimientos. Por ahora solo se debe apuntar que el artículo 2 LOSP facultaba a la autoridad competente, en el presente caso el Gobierno canario (art. 141.2 b) EACan ${ }^{2}$ ), para adoptar medidas de esta índole atendiendo a la situación sanitaria concreta de una persona o grupo de personas.

Hoy sabemos que, en aquel momento, el SARS-CoV-2 ya circulaba por España sin ser detectado. $Y$ muy posiblemente, en aquellas fechas, ya no era posible individualizar a los sujetos potencialmente portadores del patógeno vírico. Sin embargo, el confinamiento del complejo hotelero tinerfeño se adoptaba atendiendo a la situación sanitaria de un grupo determinado de personas. Y por ello, el ámbito subjetivo de las Órdenes de 24 y 27 de febrero estaba identificado con claridad pues, a pesar de dirigirse a un número elevado de destinatarios -en torno a un millar-, los mismos aparecían identificados con claridad en los Anexos I, II y III de las mismas.

Dos semanas después de estos hechos, el Gobierno riojano fue la siguiente institución autonómica que se vio en la tesitura de hacer frente a la covid-19. En esta ocasión, el brote no afectaba a un establecimiento hotelero, sino a todo un barrio de la localidad de Haro. Sin embargo, ante esta coyuntura, el Gobierno de La Rioja no ordenó en solitario el confinamiento domiciliario de

\footnotetext{
${ }^{2}$ Ley Orgánica 1/2018, de 5 de noviembre, de reforma del Estatuto de Autonomía de Canarias.
} 
una treintena de familias. Dicha decisión, efectivamente, fue adoptada, pero en el seno de un órgano de coordinación: una Junta de Seguridad con la participación de la Delegación del Gobierno en La Rioja, las fuerzas y cuerpos de seguridad y la Consejería de Salud autonómica ${ }^{3}$.

Todo apunta a que la decisión de recurrir a un órgano de coordinación para recluir a un elenco de familias en Haro, respondió a una motivación más política que jurídica. Desde un punto de vista competencial, el Gobierno riojano, al igual que el canario, era competente para adoptar medidas de este cariz, en solitario, al amparo del artículo 2 LOSP.

Ciertamente, el Estatuto de Autonomía de La Rioja ${ }^{4}$ no ha sido objeto de revisión en la última oleada de reformas estatutarias, a diferencia del ya mencionado Estatuto de Autonomía de Canarias -que hace referencia, incluso, a la vigilancia epidemiológica como competencia compartida de Canarias-. Y, por ello, el elenco de competencias que esta norma atribuye a la Comunidad Autónoma riojana, en virtud del principio dispositivo, está redactado con suma parquedad. Sin embargo, también es conocida la posición que ha mantenido el TC respecto a la exhaustividad de las cláusulas competenciales en los estatutos de segunda generación (STC 31/2010, de 28 de junio, FJ 64). Y por ello, no parece que sea muy dispar la dimensión que tienen la mayoría de títulos competenciales en los estatutos de primera y segunda generación. El artículo 9 del Estatuto riojano faculta a la Comunidad Autónoma para desarrollar y ejecutar la legislación estatal en materia de sanidad e higiene. Y dicho marco estatutario fue suficiente para que el Gobierno riojano, en octubre, acordase nada menos que el confinamiento perimetral de toda la Comunidad Autónoma -sobre este tipo de decisiones se volverá más adelante (vid. IV)- ${ }^{5}$.

Desde La Rioja debemos trasladarnos hasta Cataluña, pues el 12 de marzo de 2020 el Departamento de Interior de la Generalitat aprobó la Resolución INT $718 / 2020$, por la que se acordó restringir la salida de personas de los

\footnotetext{
${ }^{3}$ Nogueira López, A., "Confinar el coronavirus: entre el viejo Derecho sectorial y el Derecho de excepción”, El Cronista del Estado Social y Democrático de Derecho, núm. 86-87, 2020, pág. 27.

${ }^{4}$ Ley Orgánica 3/1982, de 9 de junio, de Estatuto de Autonomía de La Rioja.

${ }^{5}$ Resolución de 21 de octubre de 2020, de la Secretaría General Técnica de la Consejería de Salud y Portavocía del Gobierno, por la que se dispone la publicación del Acuerdo del Consejo de Gobierno de 21 de octubre de 2020, por el que se adoptan nuevas medidas sanitarias preventivas para la contención de la COVID-19 en el ámbito territorial de la Comunidad Autónoma de La Rioja (Boletín Oficial de La Rioja de 22 de octubre de 2020).
} 
municipios de Igualada, Vilanova del Camí, Santa Margarida de Montbui y Òdena, en los que se encontraban más de 70.000 personas. Entre esta decisión y las adoptadas en La Rioja y Canarias, la diferencia no es solo cuantitativa, por afectar a un mayor número de ciudadanos, sino también cualitativa, por no ser posible, ahora, individualizar los destinatarios de la Resolución autonómica.

El Juzgado de lo Contencioso Administrativo número 4 de Barcelona, un día después, ratificó la resolución de la Generalitat con base en los artículos 1, 2 y 3 LOSP6 6 . El artículo 2 difícilmente podía aplicarse en este momento, pues la decisión del Gobierno catalán no afectaba ya a unas personas concretas, sino a un número indeterminado de ciudadanos. Tampoco el artículo 1 LOSP, que no es sino el pórtico de la norma, y que se limita a facultar a las autoridades sanitarias para adoptar, dentro del ámbito de sus competencias, las medidas previstas en la misma.

¿Y el artículo 3 LOSP, era de aplicación? Indudablemente, este es el quid de la cuestión. Y, en lo que respecta a este particular, se plantean dos interrogantes. El primero de ellos es si la ambigüedad de dicha disposición -que permite a la autoridad competente adoptar "cualquier medida" que considere necesaria en caso de riesgo de carácter transmisible- es suficiente para permitir al poder público confinar perimetralmente un municipio. El segundo interrogante nos lleva a plantearnos si, en cualquier caso, el Derecho de la normalidad permite restringir con una intensidad tan severa, de manera genérica, innominada y colectiva, el derecho fundamental a la libertad ambulatoria de los ciudadanos (art. $19 \mathrm{CE})$.

Este segundo interrogante no tiene interés en este momento, pues en el mes de marzo de 2020 lo que se discutía era si el marco jurídico vigente daba cobertura suficiente al poder autonómico para adoptar una medida de esta intensidad. Es más, este segundo interrogante ni siquiera tiene interés a día de hoy, al menos desde una perspectiva práctica: pues el legislador, transcurrido

\footnotetext{
${ }^{6}$ El Gobierno catalán motivó esta resolución exclusivamente en normas legales de carácter autonómico, planteando esta forma de proceder un problema importante desde el punto de vista del sistema de fuentes, pues una ley ordinaria sirvió de soporte para restringir de manera muy severa un derecho cuya regulación está sujeta a reserva de ley orgánica. Tan solo subsanó esta deficiencia el recurso por parte del Juzgado de lo Contencioso Administrativo número 4 de Barcelona al principio iura novit curia.
} 
ya un año desde aquellos sucesos, no se ha planteado con el entusiasmo necesario una reforma del artículo $3 \operatorname{LOSP}^{7}$.

Por ello, todo pasa por determinar si la ambigüedad del artículo 3 LOPS permitía a la Generalitat confinar perimetralmente a 70.000 personas. $Y$ lo cierto es que, tal y como ha denunciado Sáenz Royo ${ }^{8}$, una consolidada jurisprudencia constitucional venía apuntando que la limitación de derechos fundamentales no cabía sin el amparo previo de una ley orgánica que permitiese, específicamente, tal restricción (STC 76/2019, de 22 de mayo). Indudablemente, la ambigüedad que caracteriza a la redacción del artículo 3 LOSP no podía constituir un límite "específico" a la libertad ambulatoria. Y, en consecuencia, la Resolución de la Generalitat contaba con un anclaje legal muy endeble, por no cumplir el mismo con las exigencias de previsibilidad y certeza.

Pese a ello, y como se adelantaba, el Juzgado de lo Contencioso Administrativo número 4 de Barcelona ratificó las medidas adoptadas por la Generalitat. Necessitas non habet legem, parece que concluyó el órgano judicial. Y la argumentación jurídica comenzó a deslizarse por una pendiente que, más allá del caso concreto, podía terminar por provocar más peligros que aquellos que pretendía evitar. En especial, la devaluación del Derecho como un instrumento efectivo para controlar al poder. El ordenamiento jurídico de la normalidad había quedado desbordado, y se hacía imprescindible declarar la excepción para hacer frente a un reto sanitario de una envergadura colosal.

\section{ESTADO DE ALARMA SANITARIA Y ESTADO AUTONÓMICO (PRIMERA PARTE)}

El Gobierno de España, consciente de las limitaciones del ordenamiento jurídico propio de la normalidad, activó el 14 de marzo de 2020 el Derecho constitucional de excepción. $\mathrm{Y}$, con ello, se vieron alterados los dos pilares fundamentales del Estado constitucional: derechos fundamentales y división de poderes, en su dimensión horizontal y, también, en la vertical, que es la que aquí interesa.

\footnotetext{
7 No obstante, sobre este particular se volverá más adelante, al abordar la reforma introducida en la Ley 29/1998, de 13 de julio, reguladora de la jurisdicción contencioso-administrativa por Ley $3 / 2020$, de 18 de septiembre.

${ }^{8}$ Sáenz Royo, E., "Limitar derechos fundamentales durante la pandemia", Agenda Pública, 14 de julio de 2020.
} 
La superación de una situación excepcional exige la concentración de poder y, consecuentemente, en el marco de un Estado descentralizado, la activación del Derecho Constitucional de excepción comporta una alteración del sistema de distribución territorial del poder vigente en la normalidad. El centro, una vez declarada la emergencia, pude intervenir legítimamente en el ámbito decisional subcentral. En España, ciertamente, la concentración del poder -en su dimensión vertical- ante una situación de emergencia no está contemplada expresamente en la Constitución, aunque la presume la Ley Orgánica 4/1981, de 1 de junio, de los estados de alarma, excepción y sitio (LOAES, en adelante). Y la LOAES, tal y como ha apuntado Garrido López, es una norma integrada en el bloque de constitucionalidad -y a ella debe recurrirse para enjuiciar los decretos que determinan el régimen jurídico de la situación excepcional declarada9 ${ }^{-}$.

Por ello, todo apunta a que en nuestro sistema la concentración territorial del poder frente a la crisis es constitucionalmente posible. Si bien, la intensidad con la que se observa esta dinámica está sujeta a unos límites, pues en un Estado de Derecho cualquier decisión adoptada para hacer frente a la emergencia depende de la observancia de unos elementos jurídicos básicos. En opinión de Fernández de Casadevante ${ }^{10}$, este elemento jurídico básico no es otro que el recurso al consabido principio de proporcionalidad, que comporta la realización de tres juicios sucesivos (idoneidad, necesidad y proporcionalidad en sentido estricto) que, de ser superados, permiten afirmar la constitucionalidad de una medida. Entrando en materia territorial, Velasco Caballero ${ }^{11}$ también se ha mostrado proclive a la aplicación de un test proporcionalidad para enjuiciar la constitucionalidad de la concentración de poder acordada durante la vigencia del Derecho de excepción.

\footnotetext{
9 Garrido López, C., Decisiones excepcionales y garantía jurisdiccional de la Constitución, Marcial Pons, Madrid, 2021, págs. 200-201. Más cauto a este respecto se ha manifestado L. Cotino Hueso, quien ha señalado que ""la LOAES por sí sola no es parámetro de la constitucionalidad de las medidas adoptadas". Cfr. "La (in)constitucionalidad de las restricciones y suspensión de la libertad de circulación por el confinamiento frente a la covid", en C. Garrido López (coord.), Excepcionalidad y Derecho: el estado de alarma en España, op. cit.

10 Fernández de Casadevante, P., "La crisis de los controladores aéreos y la covid-19 como emergencias constitucionales insuficientemente regladas. Propuestas de lege ferenda para el estado de alarma", en C. Garrido López (coord.), Excepcionalidad y Derecho: el estado de alarma en España, Fundación Manuel Giménez Abad, Zaragoza, 2021.

11 Velasco Caballero, F., "Estado de alarma y distribución territorial del poder", El Cronista del Estado Social y Democrático de Derecho, núm. 86-87, 2020, pág. 80.
} 
Es cierto que el TC, cuando conoce de controversias de carácter territorial, acude desde fechas recientes a un test de este tenor-cuyo ámbito de aplicación se había circunscrito tradicionalmente a supuestos de violación de derechos fundamentales- (v. gr. STC 8/2018, de 25 de enero). Y también lo es que el artículo 1.2 LOAES establece que las medidas aprobadas estando declarado un estado excepcional, se adoptarán de manera proporcionada.

No obstante, hay que advertir que el artículo 1.2 LOAES fue redactado en un momento en el que el TC no había desarrollado su jurisprudencia sobre el test de proporcionalidad $y$, en consecuencia, ésta no tiene que identificarse necesariamente con la proporcionalidad a la que alude la norma. Por otro lado, cabe señalar que el recurso por parte del TC a un test de proporcionalidad para resolver controversias territoriales ha tenido lugar en una coyuntura ordinaria, no excepcional. De hecho, cuando la excepcionalidad ha imperado, el TC se ha decantado por un simple test de razonabilidad para resolver una controversia de naturaleza territorial (STC 89/2019, de 2 de julio) ${ }^{12}$. Y la mejor doctrina ha avalado esta forma de proceder ${ }^{13}$. Por lo que todo parece apuntar a que, las decisiones centrales con repercusión territorial adoptadas durante la emergencia, en tanto que razonables, deben entenderse conformes a la Constitución.

Tras la aprobación del RD 463/2020, de 14 de marzo, el Estado dictó normas sobre materias de competencia autonómica, que "desplazaron" a las subcentrales, por ser aquéllas razonables para superar la crisis ${ }^{14}$. Si bien, como precisa el profesor Solozábal en esta misma obra, este "desplazamiento" no comportó un supuesto de aplicación de la cláusula de prevalencia, contemplada en el artículo 149.3 CE. El Derecho de excepción tiene su propia lógica, y la concentración de poder en el centro durante la emergencia no puede encontrar soporte normativo en una disposición propia de la normalidad.

\footnotetext{
12 Es cierto que el instituto de la coerción estatal, previsto en el artículo $155 \mathrm{CE}$, y el Derecho de excepción, previsto en el artículo $116 \mathrm{CE}$, no son figuras intercambiables, pero también que ambos instrumentos responden a una lógica muy similar: modular transitoriamente la aplicación de la Constitución para garantizar su propia supervivencia.

13 Aragón Reyes, M., "Tribunal Constitucional y consolidación del Estado: una mirada institucional", ponencia impartida en el marco de la Jornada "Miradas diferentes al Tribunal Constitucional", organizada por la Fundación Manuel Giménez Abad el 16 de febrero de 2021.

${ }^{14} \mathrm{La}$ razonabilidad de las medidas puede presumirse en la medida en que la periferia no impugnó desde una perspectiva competencial las disposiciones aprobadas por el centro.
} 
El poder autonómico, pese a que la concentración de poder no está expresamente contemplada en la Constitución y tan solo la presume la LOAES, aceptó con naturalidad que la declaración de la emergencia otorgaba al poder central un papel protagonista. En ocasiones, es cierto, se abogó por superar la declaración de la emergencia, y permitir así que la periferia recuperase un mayor protagonismo político ${ }^{15}$. Pero nunca fue objeto de discusión que la activación del Derecho de excepción alteraba transitoriamente el sistema de distribución territorial del poder.

Las CCAA, durante la emergencia, pudieron continuar adoptando las decisiones que estimasen pertinentes para superar la crisis. Su validez dependía de que las mismas fuesen dictadas dentro de su ámbito competencial -comercio interior, salud pública...-. Y su eficacia de que éstas no fuesen contrarias a las dictadas por el Estado; una cuestión que no siempre es sencillo de dilucidar. Un buen ejemplo de ello es la Orden de 17 de abril, del Departamento de Agricultura, Ganadería y Medioambiente del Gobierno de Aragón, que autorizó expresamente la actividad cinegética sobre las poblaciones de jabalí, conejo, corzo, ciervo y cabra montés, atendiendo al grave riesgo que su sobrepoblación -favorecida por el confinamiento domiciliario- podía irrogar en los cultivos.

Desde el punto de vista competencial, es incuestionable que la Comunidad Autónoma aragonesa es competente para acometer una regulación de este tenor (art. 71.23 EAAr). Y por ello, puede concluirse con facilidad que la Orden de 17 de abril era válida. Ahora bien, desde el punto de vista de su eficacia, ¿entraba la norma aragonesa en contradicción con el marco jurídico de la excepción dictado por el Estado? El artículo 7 RD 463/2020, de 14 de marzo, prohibía el tránsito por la vía pública de manera generalizada. El mismo solo era posible cuando concurrían una serie de supuestos tasados (adquisición de alimentos, cuidado de mayores...), así como cuando se trataba de una "actividad de análoga naturaleza" a las taxativamente enumeradas. El debate, en consecuencia, giraba en torno a si una Comunidad Autónoma era competente para determinar el concepto jurídico indeterminado "actividad de análoga naturaleza".

15 Cfr. "Torra pide a Sánchez que levante el estado de alarma o devuelva las competencias a Catalunya", La Vanguardia, 25 de abril de 2020. Disponible en: https://www.lavanguardia.com/politica/20200425/48709889184/torra-pide-sanchez-levanteestado-de-alarma-devuelva-competencias.html 
La cuestión es vidriosa, porque la Comunidad Autónoma, lejos de estar regulando simplemente la caza -para lo que tiene competencia exclusiva-, también estaba interviniendo en el modo en el que debía superarse la crisis sanitaria. Y lo estaba haciendo, además, en un momento en el que el poder central no había decidido descentralizar la excepción, tal y como ocurriría unos meses más adelante (tercera fase de la desescalada, en junio, y RD 926/2020, de 25 de octubre). La Orden aragonesa, de facto, fue eficaz, pues quienes desarrollaron aquellos días la actividad cinegética no fueron sancionados administrativamente. Sin embargo, la eficacia de esta norma parece que solo fue posible porque la misma fue adoptada con la aquiescencia del Ministerio de Agricultura, que había instado previamente al poder subcentral para que adoptase medidas en este sentido. De no haberse dado tal aquiescencia, la eficacia de esta decisión hubiese sido mucho más discutible. En un escenario en el que las CCAA no eran autoridades delegadas en la gestión de la excepción, parece que, desde un punto de vista técnico, habría sido más acertado que hubiese sido el propio poder central el que dictase una disposición con este contenido ${ }^{16}$.

Las CCAA también ejercitaron durante aquellos meses con eficacia, aunque quizás sin eficiencia, algunas de sus competencias más nítidamente ejecutivas. Entre ellas destaca, muy especialmente, la compra descentralizada de material sanitario durante las primeras semanas de crisis, que sirvió para poner de manifiesto la falta de capacidad del Ministerio de Sanidad para liderar su compra centralizada. $\mathrm{E}$, igualmente, puso de relieve que la descoordinación en la acción autonómica, y la ausencia de lealtad institucional -que impone a las partes tener en cuenta en su actuar el interés general-, provocó que el sector público incurriera, muy posiblemente, en unos costes más elevados que si las adquisiciones de material se hubiesen realizado de manera conjunta.

En definitiva, la declaración del estado de alarma comportó una concentración importantísima del poder en manos del centro, pero esta concentración, por imposibilidad material, no fue completa. La debilidad de la estructura ministerial para centralizar las compras puso de relieve que, si bien el artículo $116 \mathrm{CE}$

\footnotetext{
16 Por el contrario, como se tendrá ocasión de comprobar, la Comunidad Autónoma sí que era autoridad delegada cuando, unos meses después, fue dictada la Orden AGM/1127/2020, de 18 de noviembre, por la que se declara como situación de necesidad el control de poblaciones cinegéticas que generan graves riesgos y amenazas, durante la vigencia de los confinamientos perimetrales establecidos en la Comunidad Autónoma de Aragón.
} 
atribuye implícitamente al centro un título competencial universal, en la esfera ejecutiva dicho título esta constreñido por límites de carácter fáctico.

El estado de alarma declarado por RD 463/2020, de 14 de marzo, fue prorrogado quincenalmente; siendo la prórroga que nos merece un mayor interés desde una perspectiva territorial la última de todas, acordada por RD $555 / 2020$, de 5 de junio. La principal nueva de esta disposición es su artículo 6.1, que atribuía a quien ostentaba la presidencia de cada Comunidad Autónoma la condición de autoridad delegada, a los efectos de gestionar, dentro del contexto del Derecho de excepción, la última fase de la desescalada. El RD 514/2020 ya había contemplado la posibilidad de que, en la conocida como fase 1, el poder autonómico aplicase las medidas adoptadas por el Gobierno de España de conformidad con el de la Comunidad Autónoma. EI RD $555 / 2020$, sin embargo, es innovador porque residencia en el ámbito decisional autonómico íntegramente la gestión de la fase 3. Y, con ello, se experimentó por vez primera la posibilidad de descentralizar de manera generalizada la emergencia, yendo más allá de la literalidad de la LOAES.

El artículo 7 LOAES habilita, en el marco del estado de alarma, a que el Gobierno de España delegue en un presidente autonómico la gestión de la excepción cuando la declaración de la alarma afecte al territorio de una Comunidad Autónoma. La norma, efectivamente, no permite delegar la gestión de la excepción a todos los presidentes autonómicos, cada uno dentro de los confines de su Comunidad, cuando la crisis afecte a todo el territorio nacional. Ahora bien, ¿el hecho de que dicha delegación generalizada no esté expresamente prevista por la norma comporta que la misma sea inconstitucional? Sobre ello se volverá en el $\mathrm{V}$ apartado de este trabajo, en el que se abordan las repercusiones territoriales del estado de alarma declarado por RD 926/2020, pues fue entonces cuando la descentralización de la emergencia alcanzó su máximo exponente. Lo que procede en este momento es analizar la capacidad de intervención que tuvo el poder subcentral para hacer frente a la crisis sanitaria una vez que el estado de alarma declarado en marzo decayó el 21 de junio de 2020. 


\section{EL OXIMORÓN DE LA NUEVA NORMALIDAD}

Con la llegada de la nueva normalidad, las CCAA recuperaron su ámbito competencial ordinario. Estrictamente, nunca lo perdieron, pues como se viene sosteniendo la declaración de la alarma no afectó a la validez, sino a la eficacia, de algunas disposiciones autonómicas. Pero en términos generales se puede afirmar que el 21 de junio las CCAA volvieron a una normalidad no adjetivada desde el punto de vista competencial.

A partir de ese instante, tal y como declaró el Ministro de Sanidad, en las manos de las CCAA quedó la adopción de medidas para evitar que la situación sanitaria volviera a descontrolarse. Si bien, el propio Ministro recordó que en ningún caso cabría la limitación generalizada de derechos a los ciudadanos, pues las CCAA tan solo eran competentes para acordar restricciones "quirúrgicas" de derechos, "de personas concretas, unidades familiares, de unidades sociales mucho más restringidas, y siempre con autorización judicial"17. La suspensión generalizada de derechos solo era posible en el marco del Derecho de excepción que, felizmente, parecía dejarse atrás.

En consecuencia, en las siguientes fechas, las CCAA se limitaron a regular la forma en la que debían desarrollarse aquellas actividades en las que la interacción social era más estrecha (comercio, hostelería, cultura). Y en la mayor parte del territorio nacional tan solo excepcionalmente fue necesario que el poder autonómico, con base en el artículo 2 LOSP, acordase el confinamiento "quirúrgico" de algún grupo de individuos ${ }^{18}$. Durante el verano, la práctica totalidad de decisiones autonómicas se orientaron a la limitación del derecho fundamental a la libertad de empresa, y no a restringir la libertad ambulatoria. Es decir, el poder autonómico, consciente de que jurídicamente no podía vaciar las calles, trató de dejarlas con menos atractivos cuando la situación sanitaria así lo exigía.

El Estado, con base en los artículos $149.11^{\circ}$ y $16^{\circ} \mathrm{CE}$, había dictado el Real Decreto-ley 21/2020, de 9 de junio, en el que estableció el mínimo normativo común que debía regir el desarrollo de determinadas actividades. Si bien, esta

\footnotetext{
17 "Toda España estará en nueva normalidad el 21 de junio con movilidad libre", La Vanguardia, 10 de junio de 2020.

${ }^{18}$ Cfr. Auto de 27 de agosto del Juzgado de lo Contencioso-Administrativo número 1 de Ciudad Real, por el que se autoriza el confinamiento domiciliario de 50 individuos residentes en Bolaños de Calatrava.
} 
norma se limitaba a establecer una distancia de seguridad de un metro y medio en las actividades antedichas, y remitía a las autoridades competentes, que no eran otras que las autonómicas, la adopción de las medidas pertinentes en punto al aforo, desinfección, prevención y acondicionamiento de los establecimientos. El margen de actuación que se dejaba al nivel autonómico, en definitiva, era amplio y, teniendo en cuenta la generosa interpretación que viene realizando el TC de la cláusula competencial prevista en el artículo 149.1 $13^{\circ} \mathrm{CE}$, parece que el Real Decreto-ley 21/2020 fue una buena muestra de self-restraint por parte del centro.

Las CCAA, en diferentes normas de rango reglamentario, desarrollaron esta previsión legal, y comenzaron a establecer limitaciones de aforo. También, y yendo más allá de la literalidad del RD-Ley 21/2020, el poder autonómico acordó en normas de carácter reglamentario limitaciones horarias a la apertura de determinados establecimientos. Y se llegó a establecer, incluso, el cierre generalizado de algunos sectores económicos, como el ocio nocturno. Decisiones más que controvertidas desde un punto de vista técnico-jurídico, especialmente cuando fueron acordadas en normas de rango infralegal ${ }^{19}$.

Sin embargo, desde una perspectiva constitucional, más dudas levantaron aquellas decisiones subcentrales por las que se acordó, recurriendo al marco jurídico de la normalidad, confinamientos indiscriminados y generalizados de la población. El problema, como se recordará, ya se había planteado dos días antes de la declaración del estado de alarma en marzo, cuando la Generalitat acordó confinar perimetralmente a unas 70.000 personas en el entorno de Igualada. Y, a este respecto, ya se ha señalado ( vid. II) que, pese a que esta medida fue ratificada por la jurisdicción contencioso-administrativa, el fundamento normativo de la misma era muy discutible. En nuestro sistema de derechos fundamentales, las restricciones impuestas a los mismos deben ser previstas por el legislador de manera específica. Una disposición como el artículo 3 LOSP, que habilita en blanco al poder público para controlar enfermedades transmisibles, no puede servir de cobijo para acordar

\footnotetext{
${ }^{19}$ Así lo entendieron algunas Comunidades Autónomas, como Aragón, que para dar una cobertura jurídica adecuada a estas decisiones aprobó la Ley 3/2020, de 3 de diciembre, por la que se establece el régimen jurídico de alerta sanitaria para el control de la pandemia covid-19 en Aragón. Este particular he tenido ocasión de desarrollarlo en Guerrero Vázquez, P. "Estado de alarma sanitaria y medidas limitativas de la actividad económica", en C. Garrido López (coord.)., Excepcionalidad y Derecho: el estado de alarma en España, op. cit.
} 
limitaciones intensísimas -cuando no suspensiones- e innominadas de un derecho fundamental.

Pese a ello, desde el mes de julio de 2020 (Cataluña), y hasta octubre, cuando fue declarado con acierto y manifiesta demora un nuevo estado de alarma, fueron varias las CCAA que confinaron perimetralmente a parte de sus ciudadanos. Nos centraremos en el caso aragonés, porque su evolución presenta unas peculiaridades que parece pertinente destacar.

En Aragón, con la llegada del otoño o, quizás más acertadamente, con la llegada de las fiestas populares que algunas localidades celebran coincidiendo con el final del estío, se agravó la intensidad de los brotes que se padecían en la Comunidad desde mediados de julio. Ejea de los Caballeros (Fiestas de la Virgen de la Oliva) y Andorra (Fiestas de San Macario), fueron las dos localidades en las que las cifras de contagios alcanzaron en primer lugar niveles preocupantes, siendo necesario la adopción de medidas contundentes. El Gobierno de Aragón, para contener estos brotes, dictó las Órdenes SAN/832/2020 de 8 de septiembre, y SAN/846/2020 de 10 de septiembre, por las que se acordó, respectivamente, el confinamiento perimetral de las dos localidades antedichas. Ambas disposiciones impedían la entrada y salida en los respectivos municipios, salvo por una serie de motivos tasados que recordaban peligrosamente a aquellos estipulados en el RD 463/2020, de 14 de marzo, por el que se declaró el estado de alarma en primavera. A saber, el cumplimiento de obligaciones laborales o profesionales, el retorno al lugar de residencia, cuidado de mayores, razones de fuerza mayor... Pese a ello, al igual que ocurrió con el caso de lgualada en marzo, las medidas restrictivas de la libertad ambulatoria fueron avaladas por juzgados de lo ContenciosoAdministrativo de Zaragoza ${ }^{20}$ y Teruel.

Motivos políticos hacían ahora inviable la declaración de un nuevo estado de alarma, pues en el imaginario colectivo esta institución estaba asociada a un confinamiento domiciliario muy severo. De modo que el Gobierno de Aragón no

\footnotetext{
${ }^{20}$ Resulta llamativo el cambio de criterio del Juzgado de lo Contencioso-Administrativo número 1 de Zaragoza, pues este mismo órgano judicial, en su Auto de 14 de marzo, declinó pronunciarse sobre una Orden de la Consejería de Sanidad de ese mismo día, por entender que a la jurisdicción ordinaria tan solo le correspondía conocer sobre actos dictados en ejecución de normas de carácter general. Y aquella Orden de 14 de marzo, al igual que la de 8 de septiembre, se dirigía a un grupo indeterminado, e indeterminable, de personas.
} 
tenía ningún incentivo para solicitar la declaración del estado de alarma al Gobierno de España, ni este último parecía interesado en declararlo finalmente.

Este criterio político puso a los órganos judiciales entre la espada y la pared pues, o avalaban unas medidas adoptadas con base en un fundamento jurídico endeble -máxime cuando el artículo 3 LOSP no había sido reformado-, o permitían que la segunda ola de la pandemia se desbordase. Pero la disyuntiva es, en cierto modo, ficticia, pues estaba provocada por la decisión del poder ejecutivo de no declarar en tiempo y forma un nuevo estado de alarma -que de manera garantista había permitido superar la primera ola de la pandemia-.

Como no podía ser de otra manera, pronto la situación de emergencia sanitaria desbordó las fronteras de Aragón. Tras la publicación de la Orden comunicada del Ministro de Sanidad de 30 de septiembre, que elevó a obligatoria una propuesta acordada en el Consejo Interterritorial de Salud, todas las CCAA, con independencia del sentido de su voto en el Consejo, quedaron obligadas a acordar confinamientos perimetrales en aquellos municipios de más de 100.000 habitantes en los que concurriesen una serie de circunstancias alarmantes (más de 500 contagios por cada 100.000 habitantes, más de un 10\% de tasa de positividad y una ocupación en las unidades de cuidados intensivos superior al $35 \%$ ).

Con mayor o menor convencimiento, las Comunidades Autónomas comenzaron a acordar, por Orden, confinamientos perimetrales. En ocasiones estas decisiones se adoptaban por obligación, como es el caso de la Comunidad de Madrid, que por Orden 1273/2020, de 1 de octubre, impidió la entrada y salida de diez municipios de la Comunidad, incluida la capital, de más de 100.000 habitantes. Y, en otras, por voluntad propia, como es el caso del Gobierno de Aragón, que por Orden SAN/957/2020, de 7 de octubre, acordó confinar perimetralmente La Almunia de Doña Godina, municipio zaragozano de menos de 8.000 habitantes y, por ello, situado al margen del ámbito subjetivo de la Orden comunicada del Ministro de Sanidad de 30 de septiembre.

Lo relevante, en todo caso, es que la ratificación de estas medidas no correspondía ya a los juzgados de lo contencioso-administrativo, sino a los Tribunales Superiores de Justicia. En efecto, la Ley 3/2020, de 18 de septiembre, atribuyó a estos órganos judiciales la ratificación de medidas 
adoptadas por las autoridades sanitarias que limitasen derechos fundamentales cuando sus destinatarios no estuviesen identificados individualmente.

La constitucionalidad de esta norma procesal presenta dos sombras. En primer lugar, la reforma de la LJCA da por descontado que las suspensiones generalizadas de derechos fundamentales tienen cabida en el Derecho de la normalidad y, por ello, pretende dar una pátina de legalidad a la elusión deliberada del Derecho de excepción. En segundo lugar, aun admitiendo que la suspensión indiscriminada de derechos tiene cabida en el marco de la normalidad, que ya es mucho admitir ${ }^{21}$, el legislador, al aprobar la reforma de esta la ley procesal, de carácter ordinario, habría eludido la reforma de la LOSP, de carácter orgánico, que es donde debería estar contemplada a lo sumo esta restricción. Por todo ello, y alguna otra cuestión adicional no menor ${ }^{22}$, el TSJ de Aragón denegó la ratificación de la resolución del Gobierno aragonés que confinaba perimetralmente La Almunia de Doña Godina (Auto 89/2020, de 10 de octubre).

El camino parecía claro: afrontar la segunda ola de la pandemia exigía adoptar medidas que solo volvían a tener cabida al amparo del Derecho de excepción. Así ocurrió en la Comunidad de Madrid, donde, tras la negativa del TSJM a ratificar los confinamientos perimetrales acordados por Orden 1273/2020, se procedió a la declaración del estado de alarma por Real Decreto 900/2020, de 9 de octubre. $Y$ así ocurrió, también, en el resto del territorio nacional unas semanas después, una vez aprobado y publicado el Real Decreto 926/2020, de 25 de octubre. No obstante, entre principios y finales de octubre acontecieron

21 En este sentido, solo cabe compartir la posición sostenida por la profesora Carmona Contreras, quien ha señalado que las medidas restrictivas de la libertad dirigidas indiscriminadamente a todos los ciudadanos, con independencia de que se encuentran contagiados o no, son una excepcionalidad que solo deberían tener cabida en el marco del Derecho de excepción. Cfr. "Pandemia y restricción de derechos fundamentales", El País, 24 de octubre de 2020.

22 El Tribunal puso de relieve, con acierto, que la función de la jurisdicción es realizar un juicio de ponderación entre intereses de carácter general (la salud pública) y particular (la libertad ambulatoria de un sujeto individualizable) [cuestión de inconstitucionalidad elevada al Tribunal Constitucional el 4 de noviembre y admitida a trámite el 16 de febrero de 2021]. Velasco Caballero ha considerado que la función de realizar un juicio de ponderación entre el interés general y otro no individualizable, debe entenderse contenida en el artículo 117.4 CE. Cfr. "Cuestión de inconstitucionalidad contra la ratificación judicial de medidas sanitarias", Blog de Francisco Velasco, 15 de noviembre de 2020. Si bien, resulta difícil situar en el mismo plano el juicio de ponderación que aquí se propone y otras funciones atribuidas a Jueces y Tribunales al amparo del artículo 117.4 CE, donde sus funciones siguen estando relacionadas con partes identificables: Juntas electorales, Registro Civil, Jurados provinciales de expropiación o actos de jurisdicción voluntaria. 
en Aragón una serie de acontecimientos, de relevancia jurídico-pública, que merecen ser destacados aquí.

En efecto, una vez que el TSJA acordó no ratificar el confinamiento perimetral de La Almunia, la situación epidemiológica continuó empeorando en toda la Comunidad. Tal y como había advertido el propio órgano judicial, las medidas adoptadas por el Gobierno de Aragón, muy posiblemente, eran necesarias para atajar la propagación del virus, pero el marco normativo esgrimido por el Gobierno no era el acertado. El 10 de octubre se notificaron en Aragón 590 positivos. Una semana después, dicha cifra ascendió a los 680 positivos diarios. Y, solo cuatro días más tarde, se registraron casi 900 contagios en un día. Ante esta tesitura, ni el Gobierno de España declaró el estado de alarma en Aragón, ni el Gobierno de Aragón solicitó su declaración. Muy al contrario, el ejecutivo aragonés, en la convicción de que la legalidad ordinaria le permitía gestionar la crisis, diseñó un sistema para eludir el control judicial por parte del órgano encargado de velar por la legalidad de sus actuaciones.

Es cierto que, por entonces, otros TSJs, como el de Castilla y León ${ }^{23}$ o el de Navarra ${ }^{24}$ habían avalado el confinamiento perimetral de algunos municipios. Si bien, estos órganos judiciales habían avalado las medidas de los ejecutivos autonómicos, en primer lugar, eludiendo pronunciarse sobre la jurisprudencia constitucional en punto a la previsibilidad que debe caracterizar cualquier limitación a un derecho fundamental. Es decir, omitiendo, ante una situación de necesidad, los problemas de constitucionalidad que planteaba justificar un confinamiento no individualizado en la LOSP. Por otro lado, estos órganos judiciales tampoco hicieron referencia a las importantes dificultades teóricas que entrañaba, para la jurisdicción ordinaria, controlar suspensiones generalizadas de derechos fundamentales, por tratarse de procedimientos en los que se niega audiencia a los interesados sencillamente por imposibilidad material, no por razones de urgencia. Pero, al margen de todo ello, lo verdaderamente llamativo de la forma de proceder del ejecutivo aragonés es que, con independencia de lo que hiciesen el resto de TSJs, su órgano de control había fijado un rumbo que, en un Estado de Derecho, en el que rige el principio de separación de poderes, debía de ser observado.

23 Auto TSJ CL 63/2020, de 24 de septiembre.

24 Auto TSJ N 25/2020, de2 de octubre. 
En otras CCAA, como el País Vasco, cuando el órgano de control de su ejecutivo rechazó la posibilidad de que un Gobierno autonómico limitase generalizadamente derechos fundamentales ${ }^{25}$, esta institución procedió a solicitar al Gobierno de España la declaración del estado de alarma ${ }^{26}$. El Gobierno de Aragón, por el contrario, decidió aprobar dos decretos-leyes (7/2020, de 19 de octubre y 8/2020, de 21 de octubre) para confinar perimetralmente las tres capitales de provincia aragonesas. El primero de ellos habilitaba a la autoridad sanitaria para acordar confinamientos perimetrales cuando concurriesen unas circunstancias minuciosamente detalladas. En lo que a esto respecta, la norma dotaba de previsibilidad y certeza a la actuación gubernamental, en la línea de lo exigido por la jurisprudencia constitucional. Y, en consecuencia, Aragón se separaba del camino iniciado por la Generalitat catalana en julio que, tras ver cercenada por la jurisdicción su pretensión de confinar perimetralmente algunos municipios de la Comarca del Segrià, aprobó el Decreto-ley 27/2020, de 13 de julio: una norma que se limitaba a contemplar la posibilidad de que el Gobierno autonómico confinase perimetralmente a sus ciudadanos, pero sin regular las condiciones que debían concurrir para proceder de tal modo.

El Decreto-ley aragonés 7/2020, en todo caso, asumía la regulación de una materia que, en buena técnica jurídica, debía quedar vedada al legislador de urgencia; y en mayor medida al legislador autonómico. En efecto, el establecimiento de límites de este cariz a la libertad ambulatoria (art. 19 CE) solo corresponde, a lo sumo, al legislador orgánico (art. $81 \mathrm{CE}$ ). Además, el Decreto-ley 7/2020 parte del presupuesto de que el derecho de la normalidad puede acordar restricciones genéricas e innominadas de derechos fundamentales. $Y$ esta consideración, tal y como se viene desarrollando, dista de ser una cuestión pacífica hoy en día.

Pese a ello, la disposición que merece un mayor reproche no es el Decreto-ley 7/2020, sino el 8/2020, dictado solo tres días después. El mismo constituyó una suerte de norma autoaplicativa por la que quedaron confinados, directamente, los municipios de Zaragoza, Huesca y Teruel. Y, como no pasa desadvertido, la

25 Auto TSJ PV 52/2020, de 22 de octubre, que cita el Auto TSJA de 10 de octubre, sobre el caso La Almunia.

26 "Iñigo Urkullu pide a Pedro Sánchez un estado de alarma para toda España pero con "mando y gestión" de cada autonomía", El Mundo, 23 de octubre de 2020. 
única finalidad de dotar a esta decisión de rango de ley era eludir el control judicial de la actuación gubernamental.

En los meses anteriores se había advertido, en ocasiones, que para los ciudadanos el Derecho de la excepción era mucho menos garantista que el de la normalidad; pero la actuación del ejecutivo aragonés puso de manifiesto justo lo contrario. El Gobierno de Aragón, con su forma de proceder, hizo saltar por los aires el doble sistema de control judicial defendido por quienes habían apostado por superar la crisis recurriendo, exclusivamente, al Derecho de la normalidad. En efecto, la actuación gubernamental dejaba sin efecto el control judicial de carácter abstracto llevado a cabo ex ante por los Tribunales Superiores de Justicia. Y tan solo subsistía el control judicial ex post, sobre la acción gubernamental concreta.

Este último control, indudablemente, tiene también cabida en el marco del Derecho de excepción. Pero este Derecho, además, se caracteriza por reforzar el control parlamentario del ejecutivo, al imponer que cualquier restricción de derechos tenga, de un modo u otro, y para cada situación de emergencia, el respaldo expreso de los representantes de los ciudadanos. Desde un punto de vista democrático, parece que un sistema de estas características es mucho más acertado que el control judicial ex ante ahora eludido por el Gobierno aragonés ${ }^{27}$. Precisamente por este motivo, por existir en el Derecho de excepción un doble sistema de garantía -parlamentario y judicial ${ }^{28}$-, en este trabajo se defiende la necesidad de recurrir al mismo para imponer limitaciones no individualizables de un derecho fundamental. $Y$ por ello, creemos, tras la aprobación del Decreto-ley aragonés 8/2020, devino definitivamente imprescindible la declaración de un nuevo estado de alarma para superar con garantías, políticas y jurídicas, la crisis sanitaria.

\footnotetext{
${ }^{27}$ Ello sin olvidar que, como ya se ha esgrimido, el control judicial por excelencia tiene lugar en el caso concreto con partes identificadas.

${ }^{28}$ Sin olvidar, evidentemente, el control jurisdiccional por parte del TC de la declaración del estado excepcional, cuyo control, por tratarse de una decisión con rango de ley, corresponde necesariamente al máximo intérprete de la Constitución. Sobre la naturaleza jurídica de las decisiones excepcionales y su control jurisdiccional. Cfr. Garrido López, C., Decisiones excepcionales y garantía jurisdiccional de la Constitución, op. cit. M. Aragón Reyes, además, ha apostado por introducir en la LOTC un procedimiento preferente y sumario para controlar las disposiciones que declaran la excepción, y evitar así el cauce procedimental del recurso de inconstitucionalidad que, inevitablemente, demoraría el pronunciamiento del máximo intérprete de la Constitución mucho más de lo deseable. Cfr. "Epílogo", Campos, P.; Durán Alba, F. Los efectos horizontales de la COVID-19 sobre el sistema constitucional, Fundación Manuel Giménez Abad, Zaragoza, 2021.
} 


\section{ESTADO DE ALARMA SANITARIA Y ESTADO AUTONÓMICO (SEGUNDA PARTE)}

La activación del Derecho de excepción por RD 926/2020, de 25 de octubre, dotaba de una mejor cobertura jurídica a la respuesta que el poder público debía dar a la segunda ola de la pandemia. Si bien, la declaración de un nuevo estado de alarma abrió una serie de interrogantes que solo cabe apuntar en los últimos compases de este trabajo.

En primer lugar, destaca la decisión de prorrogar el estado de alarma por un plazo exorbitante, hasta el 9 de mayo. Un plazo tan dilatado de prórroga, aunque no violenta la literalidad de la Constitución, sí que puede haber afectado a su espíritu ${ }^{29}$. La decisión del propio Congreso de los Diputados de renunciar a su función constitucional de control es sumamente perniciosa pues, como se acaba de apuntar, nuestro sistema racionaliza la excepción, precisamente, reforzando el control parlamentario del ejecutivo. Y por ello, la renuncia del Congreso de los Diputados de su función controladora durante más de seis meses, ha aproximado peligrosamente el sistema que aquí se defiende (Derecho Constitucional de excepción) al que se ha descartado (Derecho de la normalidad) -en el que el control ex ante de la actuación gubernamental había comenzado a ser eludido recurriendo a la legislación de urgencia-.

Sin embargo, por tener un impacto nítidamente territorial, en este trabajo debe abordarse con un mayor detenimiento la configuración en el RD 926/2020 de un estado de alarma de carácter descentralizado, otorgando a los presidentes de las CCAA un papel protagonista (art. 2.2). Esta decisión, a priori, podía estar justificada si se atendía a las marcadas diferencias existentes entre la situación sanitaria de las CCAA. Si bien, tampoco puede obviarse que, en la práctica, la misma terminó por provocar que los diferentes niveles de poder eludiesen asumir medidas impopulares ${ }^{30}$.

\footnotetext{
${ }^{29}$ M. Aragón Reyes, "La prórroga del estado de alarma", El País, 28 de octubre de 2020.

30 Pocos días antes de la Navidad de 2020, ningún nivel de poder, ni el central ni el subcentral, estaba dispuesto a asumir el coste de incrementar las restricciones que debían regir en las reuniones sociales de aquellos días. Y ello pese a que todos indicadores ponían de manifiesto que la situación epidemiológica se está volviendo a descontrolar.
} 
En cualquier caso, a nosotros lo que nos interesa es la pertinencia de esta decisión desde una óptica jurídica. Tal y como ya se ha señalado (vid. III), el artículo 7 LOAES habilita al Gobierno de España, en el marco del estado de alarma, a delegar en un presidente autonómico la gestión de la excepción cuando la declaración de la alarma afecte al territorio de una Comunidad Autónoma. Pero la norma nada estipula acerca de dicha delegación a todos los presidentes autonómicos, cada uno dentro de los confines de su Comunidad, cuando la crisis afecta a todo el territorio nacional.

Este silencio de la LOAES puede servir para criticar la delegación que el RD 926/2020 acometió en favor de los presidentes de las CCAA. Si bien, no puede olvidarse que, de todas las ocasiones en las que se ha declarado la alarma en España, solo en una se ha respetado estrictamente la literalidad del artículo 7 LOAES. EI RD 1673/2010, de 4 de diciembre, designó autoridad delegada al JEMAD, en ausencia de cualquier previsión normativa. EI RD 463/2020, de 14 de marzo, hizo lo propio respecto a diferentes ministros (defensa, interior, transportes y sanidad). Y el RD 926/2020, de 25 de octubre, consideró autoridad delegada a los presidentes autonómicos. Paradójicamente, la única vez en la que no se contempló delegación alguna fue, precisamente, en el supuesto que mejor encajaba en la letra del artículo 7 LOAES. En efecto, el RD 900/2020, de 9 de octubre, por el que se declaró el estado de alarma exclusivamente en una serie de municipios de la Comunidad de Madrid, estableció que la única autoridad competente era el Gobierno de España.

La delegación en los presidentes autonómicos acordada por RD 926/2020 plantea dudas no menores en punto al control, político y judicial, del ejercicio de dicha delegación. ¿Qué papel pueden jugar los parlamentos autonómicos a la hora de controlar estas decisiones? ¿Y los Tribunales Superiores de Justicia ${ }^{31}$ ¿El control judicial debe corresponder al Tribunal Supremo ${ }^{32}$ ¿El Gobierno de España debe de impugnar la decisión autonómica ante los Tribunales, si no

31 Cfr. "EI TSJA se declara competente para valorar la legalidad de las restricciones en Aragón", Heraldo de Aragón, 18 de diciembre de 2020. Disponible en:

https://www.heraldo.es/noticias/aragon/2020/12/18/tsja-se-declara-competente-para-valorarlegalidad-de-restricciones-en-aragonara-coronavirus-pandemia-

1411021.html\#: :text=El\%20Tribunal\%20Superior\%20de\%20Justicia,Javier\%20Lamb\%C3\%A1 n\%2C\%20por\%20delegaci\%C3\%B3n\%20del

32 Cfr. "El Tribunal Supremo admite a trámite el recurso contra el toque de queda de Castilla y León", La Vanguardia, 19 de enero de 2021. Disponible en:

https://www.lavanguardia.com/politica/20210119/6185330/tribunal-supremo-admite-tramite-

recurso-toque-queda-castilla-leon.html 
comparte el criterio del poder subcentral, o puede revocar la delegación y dictar una resolución en sentido contrario ?33 $^{33}$

Los interrogantes abiertos no son una cuestión menor, pero los mismos pueden formularse, en los mismos términos, cuando la declaración de la alarma afecte solamente al territorio de una Comunidad Autónoma y se delega su gestión en su presidente. Es decir, cuando la delegación se realiza respetando escrupulosamente lo previsto en el artículo 7 LOAES. Por ello, las dudas planteadas no pueden ser un argumento concluyente a la hora de razonar la ilicitud de la descentralización de la emergencia.

Una vez que la delegación no está prevista expresamente en la LOAES, pero tampoco taxativamente prohibida, parece que su viabilidad desde un punto de vista jurídico dependerá de que la misma supere un test de razonabilidad... que, en el presente caso, parece sobrepasarse si se atiende a las marcadas y cambiantes diferencias entre la situación sanitaria de las CCAA. Y, por ello, una cosa es que políticamente la delegación en los presidentes autonómicos haya planteado algunos problemas prácticos, y otra que jurídicamente deba concluirse su inconstitucionalidad.

A nivel comparado, el mayor o menor acierto en la gestión de la crisis sanitaria no ha dependido de la forma en la que se distribuye territorialmente el poder dentro de un Estado. La polarización política, por el contrario, parece que ha sido un factor determinante a la hora de explicar el impacto que la emergencia sanitaria ha tenido en los diferentes países. Solo así se entiende que la gestión de la crisis haya tomado dos caminos radicalmente diferentes en los dos modelos canónicos del federalismo: Alemania -donde ha primado el consenso entre las principales fuerzas políticas- y Estados Unidos -donde bajo la presidencia de Donald Trump ha ocurrido justo lo contrario-34.

La emergencia presume la unidad de poder, pero debe de ser compatible con la descentralización de su gestión. Una vez declarada la emergencia, la descentralización de la gestión debe de ser una herramienta puesta al servicio

${ }^{33}$ Esta posición, creemos que con acierto, ha sido defendida por G. Teruel Lozano, cfr. "Estado... ¿de alarma?: del Derecho líquido a la liquidación del Derecho", Hay Derecho, 25 de enero de 2021. Disponible en: https://hayderecho.expansion.com/2021/01/25/estado-dealarma-del-derecho-liquido-a-la-liquidacion-del-derecho/

${ }^{34}$ Cfr. Sáenz Royo, E., "La falta de coordinación en la pandemia: el no-fallo del Estado autonómico", Agenda Pública, 8 de octubre de 2020. Disponible en: https://agendapublica.es/lafalta-de-coordinacion-en-la-pandemia-el-no-fallo-del-estado-autonomico/ 
del poder central para aquellos supuestos en los que éste, razonablemente, entienda que la delegación puede coadyuvar a superar la crisis. Tal delegación, no obstante, debería estar bien delimitada. Y bien delimitados deberían estar, igualmente, los mecanismos de control existentes para supervisar el ejercicio de poderes exorbitantes por las autoridades subcentrales. Como señaló Kelsen, la democracia sin control es a la larga imposible ${ }^{35}$. $Y$ hoy en día, en España, la descentralización de la emergencia cuenta con un sistema de control nebuloso y, en consecuencia, endeble.

${ }^{35}$ Kelsen, H., De la esencia y valor de la democracia, KRK ediciones, Oviedo, 2006, pág. 181. 